\title{
Metode Pose to Pose untuk Membuat Animasi 3 Dimensi Islami "Keutamaan Berbuka Puasa"
}

\author{
Mahadir Muhamad Erfin Abdilah ${ }^{1}$, Juniardi Nur Fadila ${ }^{2}$, Fresy Nugroho ${ }^{3}$ \\ Program Studi Teknik Informatika, Universitas Islam Negeri Maulana Malik Ibrahim \\ Malang, Indonesia \\ 1)19650035@student.uin-malang.ac.id \\ 2) juniardi.nur@uin-malang.ac.id \\ ${ }^{3)}$ fresy@ti.uin-malang.ac.id
}

\begin{abstract}
Abstrak
Berkembangnya teknologi di bidang computer graphics memberikan kemudahan dalam mengolah suatu karya grafis salah satunya adalah animasi 3D. Dalam pembuatan animasi 3D terdapat permasalahan utama yang biasa menjadi tantangan bagi para animator. Permasalahan utama dalam pembuatan animasi 3D adalah kualitas gerakan yang kasar atau tidak terkesan nyata. Untuk membuat gerakan yang halus dan tampak nyata dapat dilakukan melalui banyak metode salah satunya adalah metode pose to pose. Animasi 3D islami berjudul Keutamaan Berbuka Puasa sebagian besar berisi gerakan dalam memperagakan taat cara berbuka puasa yang baik dan benar untuk mendapatkan keutamaan berbuka. Pembuatan animasi ini dibuat melalui software blender dengan menerapkan metode pose to pose. Sebagai hasil pembuatan paper ini, film animasi 3D berjudul Keutamaan Berbuka Puasa diharapkan dapat dibuat dengan kualitas gerakan yang bagus dengan menggunaan metode pose to pose serta dapat memberikan hiburan dan edukasi yang baik.
\end{abstract}

Kata kunci: Animasi 3D, Cerita Islami, Pose to Pose, Software Blender

\begin{abstract}
The development of technology in the field of computer graphics provides convenience in processing a graphic work, one of which is $3 D$ animation. In making $3 D$ animation there are main problems that are usually a challenge for animators. The main problem in making $3 D$ animation is the quality of the movement that is grainy or doesn't seem real. To make movements that are smooth and look real can be done through many methods, one of which is the pose to pose method. The Islamic 3D animation entitled The Virtue of Breaking the Fast mostly contains movements in demonstrating the proper and correct way of breaking the fast to get the virtues of breaking the fast. Making this animation is made through blender software by applying the pose to pose method. As a result of making this paper, it is hoped that a $3 D$ animated film entitled Virtue of Breaking Fasting is expected to be made with good movement quality using the pose to pose method and can provide good entertainment and education.
\end{abstract}

Keywords: 3D Animation, Islamic Stories, Pose to Pose, Blender Software

\section{PENDAHULUAN}

Perkembangan teknologi yang semakin pesat memberikan kemajuan diberbagai bidang, salah satunya grafika komputer. Grafika komputer merupakan suatu bidang komputer yang berkaitan dengan pembuatan dan pemanipulasian gambar secara digital [1]. Pada saat ini, grafika komputer telah memberikan banyak manfaat dalam kehidupan sehari-hari yang hasilnya bisa dilihat melalui android, komputer, televisi, dan media lain. Salah satu produk yang dihasilkan oleh teknologi grafika komputer adalah animasi. Melalui grafika komputer pengguna dapat berkomunikasi dengan komputer melalui gambar, bagan, maupun diagram [2]. Sehingga animasi dapat diolah dan dikembangkan melalui komputer dengan melalui metode-metode tertentu. 
Animasi komputer adalah suatu seni untuk membuat gambar tampak bergerak dengan menggunakan teknologi komputer [3]. Animasi merupakan suatu kegiatan untuk menghidupkan atau menggerakkan benda mati dengan memberikan dorongan kekuatan, semangat, serta emosi supaya tampak hidup dan bergerak [4]. Animasi 3D berarti animasi yang memiliki objek 3 dimensi dan animasi 2D berarti animasi yang memiliki objek 2 dimensi. Pada perkembangan grafika komputer seperti seakrang ini, animasi dibuat melalui teknologi komputer sehingga pembuatannya dilakukan dengan lebih mudah dan cepat. Dengan adanya teknologi yang maju ini, banyak tema animasi yang berhasil dibuat salah satunya animasi bertema islami. Animasi 3D tidak hanya bermanfaat sebagai hiburan saja, akan tetapi juga bermanfaat dalam bidang edukasi dan dakwah [5].

Pada masa sekarang ini ada banyak orang islam yang lalai terhadap adab berbuka puasa. Padahal adab berbuka puasa itu sangatlah penting karena mengandung keutamaan berbuka puasa. Tidak jarang penulis melihat banyak muslim kurang memperhatikan adab berbuka puasa saat berada di tempat makan. Mereka lebih mengutamakan gatgetnya dari pada adab berbuka puasa. Aktivitas dakwah pada hakekatnya merupakan pilihan strategis dalam membentuk perubahan masyarakat menuju arah yang lebih baik [6]. Oleh karena itu penulis ingin membuat sebuah animasi 3D bertema islami yang berjudul "Keutamaan Berbuka Puasa".

Animasi 3D islami berjudul "Keutamaan Berbuka Puasa" lebih menekankan dalam hal gerakan. Dan dalam pembuatan animasi hal yang penting untuk diperhatikan adalah pergerakan [7]. Untuk mengatasi pergerakan yang kurang halus dapat dilakukan dengan menggunakan salah satu metode pembuatan animasi, yaitu metode pose to pose. Metode pose to pose merupakan metode pembuatan animasi yang menekankan pada penentuan key pose [8]. Untuk membuat key pose, seorang animator harus menentukan gerakan objek dan mencari tahu gambar apa saja yang dibutuhkan untuk membuat animasi bergerak dalam scene tertentu [9]. Setelah itu, yang perlu dilakukan adalah menentukan gerakan keyframe, ekstreme, dan in between [10]. Untuk mengatur keyframe diperlukan pengaturan frame yang baik. Semakin banyak frame yang digunakan akan menghasilkan gerakan yang lambat, sebaliknya semakin sedikit frame yang digunakan akan menghasilkan gerakan yang cepat. Kelebihan dari metode pose to pose adalah waktu pengerjaan animasi lebih cepat, gerakan animasi lebih terkonsep, dan mudahnya menemukan kesalahan dalam mengatur pose [11].

Animasi 3D ini dibuat di software Blender. Software Blender merupakan sebuah alat untuk mengembangkan model mesh polygonal 3 dimensi [12]. Melalui software blender kita dapat melakukan banyak hal seperti modeling, rigging, animasi, simulasi, rendering, compositing dan motion tracking, bahkan pengeditan video dan pembuatan game [13]. Adanya berbagai fungsi, tool, serta fiturfitur yang lengkap dalam software blender memudahkan dalam membuat salah satunya animasi 3D. Pembuatan animasi 3D islami "Keutamaan Berbuka Puasa" bertujuan untuk menghasilkan gerakan animasi yang bagus sehingga dapat memberikan contoh adab berbuka puasa yang baik.

Sistematika pembahasan penelitian ini disusun dalam empat bagian sebagai berikut. Bagian pertama akan menyajikan pendahuluan yang berisi mengenai latar belakang dan animasi 3D metode pose to pose. Kemudian bagian kedua akan menyajikan Metode penelitian terkait metode dan hal-hal yang diperlukan dalam penelitian. Pada bagian ketiga akan menyajikan hasil dan pembahasan terkait pembuatan animasi 3D islami "Keutamaan Berbuka Puasa". Dan bagian keempat akan menyajikan kesimpulan sebagai hasil dari penelitian yang telah dilakukan.

\section{METODE PENELITIAN}

Pembuatan animasi dilakukan melalui beberapa tahapan yang berpengaruh pada kualitas dan jalannya animasi kedepannya. Tahapan-tahapan itu terdiri dari tahap pra produksi, tahap pasca produksi dan tahap pasca produksi. Pada tahap pra produksi, animator melakukan tahap persiapan untuk menyiapkan alat serta bahan yang dibutuhkan dalam membuat animasi [14]. Pada tahap ini, hal yang perlu disiapkan adalah desain cerita dan storyboard untuk membuat animasi pada software blender. Setelah melakukan tahap pra produksi, tahap selanjutnya adalah tahap produksi. Tahap produksi merupakan tahap yang paling lama dalam membuat animasi [11]. Tahap produksi terdiri dari beberapa tahap, yaitu modeling atau tahap untuk membentuk objek animasi, pemberian 
material atau warna, rigging atau pemberian tulang pada objek animasi supaya bisa digerakkan, animating atau tahap penggerakan objek agar menghasilkan animasi yang berkualitas, dan tahap rendering. Kemudian tahap terakhir dalam pembuatan animasi adalah tahap pasca produksi. Pada tahap pasca produksi, semua scene yang berhasil dibuat pada tahap produksi digabungkan menjadi satu dan diedit untuk menghasilkan animasi yang bagus dan menarik.

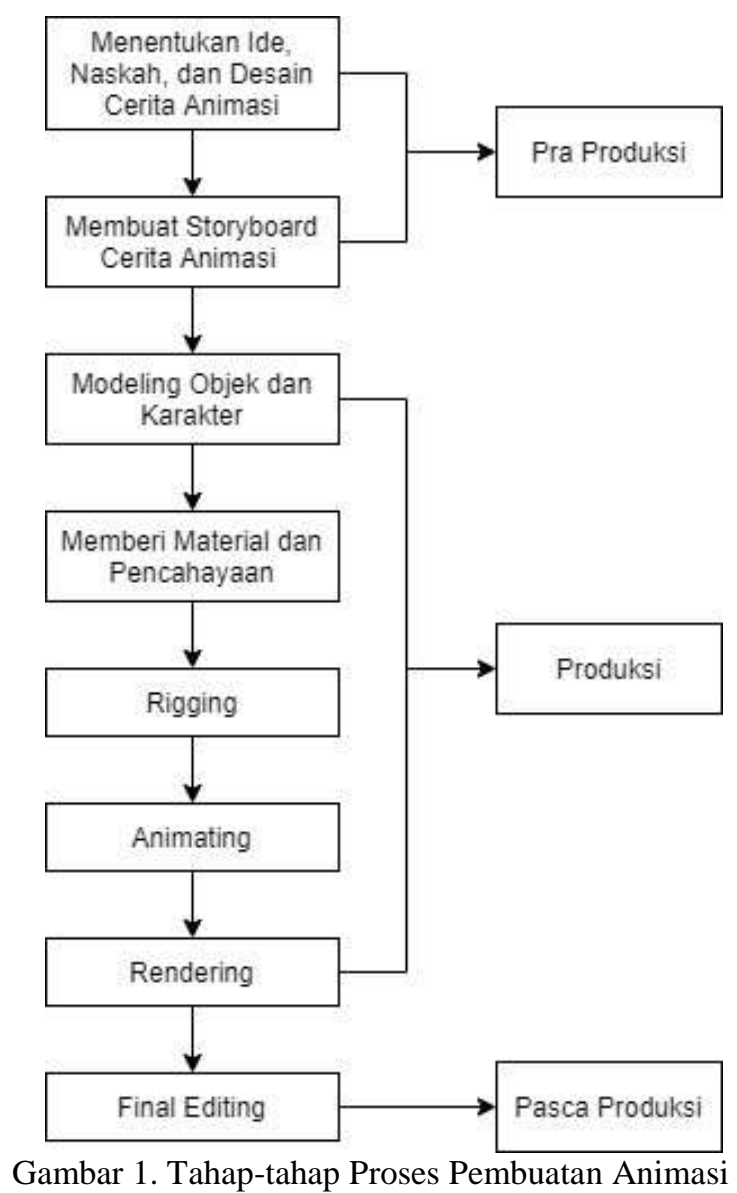

\subsection{Tahap Pra Produksi}

Tahap pra produksi merupakan tahap awal atau persiapan untuk membuat sebuah animasi. Tahap ini merupakan tahap yang akan menentukan hasil akhir animasi. Hal ini karena apabila tahap awal dari sebuah animasi tidak jelas maka hasil animasinya juga tidak jelas atau tidak sesuai dengan konsep awal yang sudah dibuat. Pada tahap pra produksi, hal yang dilakukan adalah membuat konsep animasi yang terdiri dari ide, naskah, desain cerita, dan storyboard animasi.

\subsubsection{Penentuan Ide, Naskah dan Desain Cerita Animasi}

Pada tahap awal dalam membuat animasi yaitu menentikan ide. Ide merupakan hasil pemikiran tentang cerita animasi yang akan dibuat. Ide sebenarnya adalah inti dari cerita yang harganya mahal [15]. Dengan adanya sebuah ide, maka naskah dan desain cerita dapat dihasilkan. Fungsi dari naskah adalah untuk menjaga agar animasi yang dibuat tidak keluar dari konsep yang telah ditentukan sebelumnya dan membantu dalam mengurutkan alur cerita [15]. Dari sebuah ide akan menghasilkan naskah cerita kemudian akan menghasilkan desain cerita yang bagus dan menarik sehingga layak untuk dijadikan sebuah cerita.

\subsubsection{Pembuatan Storyboard Cerita Animasi}

Setelah membuat desain cerita, tahap selanjutnya adalah membuat storyboard cerita animasi. Stroryboard memberikan gambaran sketsa dari cerita animasi. Storyboard merupakan alat 
perencanaan untuk menunjukkan secara virtual bagaimana alur cerita pengembangan animasi [16]. Animasi dapat dibuat melalui panduan dari storyboard yang telah dibuat sebelumnya. Storyboard sangat penting dalam pembuatan animasi karena storyboard berfungsi untuk menggambarkan rangkaian cerita atau deskripsi tiap scene sehingga dapat dimengerti oleh pengguna, dengan mencantumkan semua objek multimedia dan tautan ke scene lain [17].

\subsection{Tahap Produksi}

Tahap produksi merupakan tahap yang paling lama dalam membuat animasi [11]. Tahap produksi dapat berjalan lancar apabila konsep pada tahap pra produksi sudah matang dan jika ada perubahan cerita animasi maka perubahannya sedikit. Tahap produksi terdiri dari beberapa tahap, yaitu modeling atau tahap untuk membentuk objek animasi, pemberian material atau warna, rigging atau pemberian tulang pada objek animasi supaya bisa digerakkan, animating atau tahap penggerakan objek agar menghasilkan animasi yang berkualitas, dan tahap rendering.

\subsubsection{Modeling}

Langah awal dari tahap produksi adalah membuat model objek animasi atau modeling. Dalam modeling dikenal istilah poligon mesh modeling yang merupakan tahap membuat bentuk dengan memodifikasi letak point atau segmen dari sebuah objek yang terbentuk dari polygon mesh [18]. Proses modeling bertujuan untuk membentuk ukuran dan bentuk objek supaya terlihat secara visual. Di dalam software Blender, modeling objek dilakukan pada Edit Mode dengan bantuan beberapa fungsi, seperti extrude, pemberian skala, dan grab kemudian dapat ditambah modifier Mirror maupun Subdivision Surface untuk membentuk objek sesuai keinginan pembuatnya [19].

\subsubsection{Pemberian Material dan Pencahayaan (Lighting)}

Tahap selanjutnya adalah pemberian warna dan pencahayaan objek animasi. Pemberian warna objek animasi di blender dilakukan dengan menggunakan tools material yang sudah tersedia pada kolom properties dan $U V$ map pada software Blender. Langkah selanjutnya adalah pencahayaan. Pencahayaan dilakukan supaya objek animasi memeperoleh kesan yang realistis [19]. Melalui kedua tahap ini objek animasi yang sudah dibuat bisa dilanjutkan pada tahap rigging dan animating.

\subsubsection{Rigging}

Setelah melakukan modeling objek atau karakter animasi, langkah berikutnya adalah pemberian tulang pada karakter animasi. Tujuan rigging adalah untuk menambahkan suatu rangka dan sejumlah kontrol ke objek karakter yang telah dibuat sehingga animator dapat memanipulasi dan menganimasikan karakter tersebut [20]. Dengan demikian, proses pemberian pose karakter untuk animasi dapat dibuat.

\subsubsection{Animating}

Tahap produksi yang selanjutnya adalah animating. Animating merupakan penggerakan objek karakter dengan menyesuaikan pergerakannya sesuai naskah dan storyboard yang telah dibuat sebelumnya [21]. Pembuatan animasi dengan menggunakan pose to pose berarti animasi itu dibuat dengan menentukan keypose yang dibuat menurut storyboard. Keypose itu nantinya akan menjadi penentu gerakan animasi kedepannya. Setelah melakukan penentuan keypose, selanjutnya adalah menentukan efek gerak animasi atau bisa disebut extreme. Kemudian extreme diperhalus dengan melakukan in between animasi [11].

\subsubsection{Rendering}

Rendering merupakan tahap akhir dari produksi animasi yang menyatukan seluruh proses tahapan produksi, mulai dari Modeling sampai Animating sehingga menghasilkan sebuah file video [22]. Adegan-adegan yang terdiri dari tekstur, geometri, sudut pandang, dan pencahayaan akan diproses oleh program rendering untuk menghasilkan sebuah gambar digital [23]. Software blender memiliki tiga jenis render engine, yaitu Blender Render, Blender Game, dan 
Cycles Render. Cycles Render memiliki pencitraan cahaya yang baik sehingga cocok untuk dipilih sebagai tipe rendering animasi 3D [11].

\subsection{Tahap Pasca Produksi}

Tahapan terakhir dari proses pembuatan animasi adalah tahap pasca produksi. Tahap pasca produksi merupakan tahap final editing terhadap scene animasi yang telah render. Semua file hasil rendering pada bagian produksi digabungkan dan ditambahkan file audio pada tahap pasca produksi [24]. Penggabungan semua file hasil rendering yang berisi scene-scene animasi serta menambahkan file suara dapat menghasilkan sebuah animasi yang siap untuk ditampilkan. Dengan demikian, sebuah ide yang sebelumnya tertuang dalam storyboard dapat dijadikan sebuah cerita animasi yang menarik dan mengedukasi.

\section{PEMBAHASAN}

Bagian pembahasan akan membahas mengenai proses dan hasil pembuatan Animasi 3D berjudul "Keutamaan Berbuka Puasa". Pembuatan animasi ini dilakukan dari tahap pra produksi yang berisi konsep animasi. Kemudian tahap produksi yang berisi proses modeling sampai animating dengan menerapkan metode pose to pose. Tahap pasca produksi berisi proses penggabungan scene animasi yang sudah dibuat pada tahap produksi dan melakukan final editing.

\subsection{Pra Produksi}

\subsubsection{Ide dan Naskah Animasi}

Cerita animasi memiliki tema religi islami untuk menyambut bulan suci ramadhan. Ide cerita animasi didapatkan oleh penulis dari sesuatu yang dilakukan saat bulan ramadhan, yaitu berbuka puasa. Penulsi berpikir dan mengamati bahwa terkadang ada di antara orang islam yang menganggap tidak penting adab berbuka puasa. Oleh karena itu, cerita animasi ini dibuat supaya orang yang berbuka puasa dapat mendapatkan keutamaan berbuka melalui adab yang baik saat melaksanakan berbuka puasa. Ide ini selanjutnya dituangkan dalam sebuah naskan cerita animasi yang menjadi konsep awal pembuatan animasi.

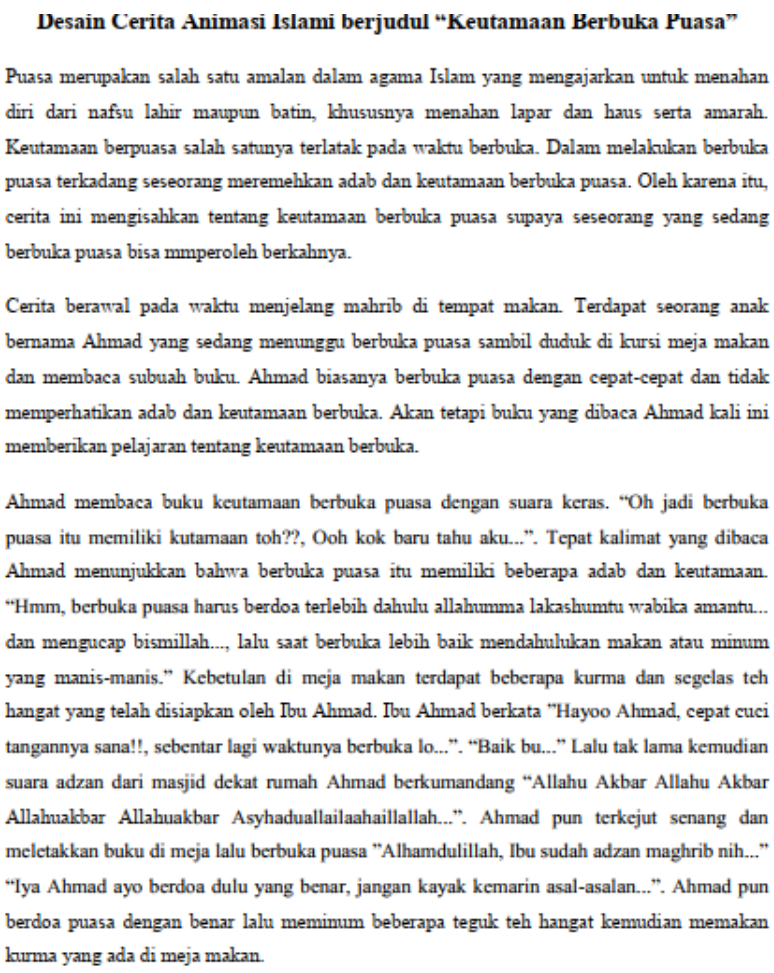

Gambar 2. Naskah Animasi 


\subsubsection{Storyboard Animasi}

Setelah naskah yang mncakup ide animasi telah dibuat, penulis merancang storyboard animasi yang dilakukan melalui menggambar pada lembar kertas. Tujuan dari pembuatan storyboard adalah untuk memudahkan penulis dalam melakukan pengambilan sudut pandang camera saat proses animating [11]. Hasil storyboard yang sudah dibuat adalah sebagai berikut.

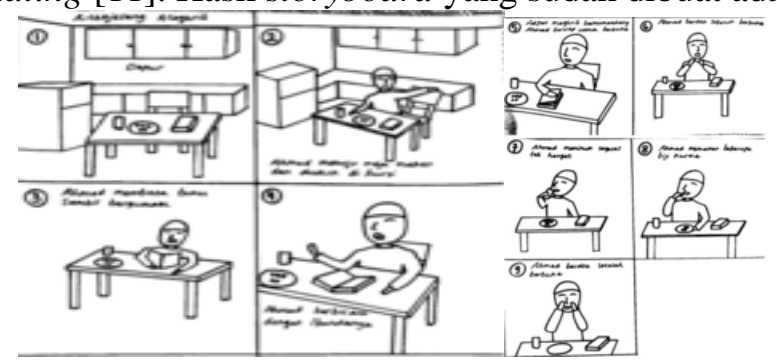

Gambar 3. Storyboard Animasi

\subsection{Produksi}

\subsubsection{Modeling Objek dan Karakter}

Pada tahap modeling, objek dan karakter yang berkaitan dengan animasi dibuat melalui software Blender. Pembuatan objek dan karakter pada dasarnya hampir sama, yaitu melalui Edit Mode kemudian memberikan skala, rotasi, dan posisi. Untuk membentuk objek atau karakter dari sebuah mesh kubus dapat dilakukan dengan menggunakan fitur dan tools seperti scale, rotate, dan grab serta menambahkan modifier subdivision surface pada karakter supaya permukaannya menjadi halus. Modifier dapat ditambahkan dengan memilih karakter dan menambahkan modifier subdifvision surface melalui fitur modifier di software Blender.

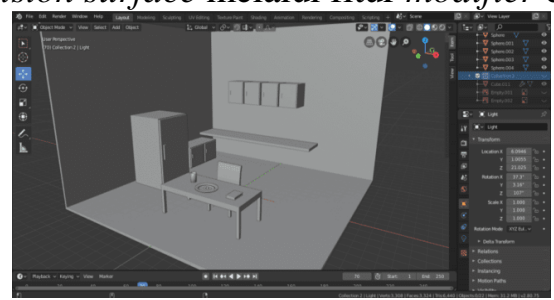

Gambar 4. Modeling Objek Dapur

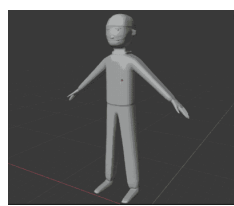

Gambar 5. Modeling Karakter

\subsubsection{Material}

Setelah selesai melakukan tahap modeling, objek dan karakter memiliki bentuk yang masih polos tanpa warna. Penulis memberikan warna pada objek dan karakter dengan memanfaatkan fitur material. Material ini dapat berfungsi untuk memberikan warna pada objek dan karakter agar terlihat lebih menarik. Gambar 6 adalah hasil pemberian material oleh penulis.

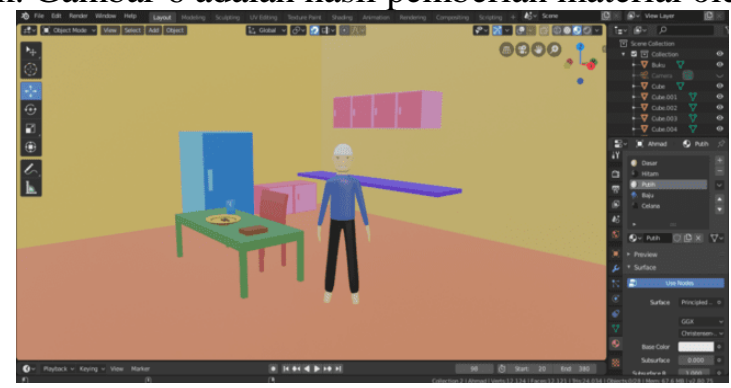

Gambar 6. Material Objek dan Karakter 


\subsubsection{Rigging}

Tahap rigging dilakukan dengan menambahkan tulang pada karakter. Tujuan dari tahap rigging adalah agar mempermudah proses pemberian pose [11]. Untuk mempercepat pemberian tulang pada karakter dapat dilakukan dengan memilih armature Human (Meta-rig).

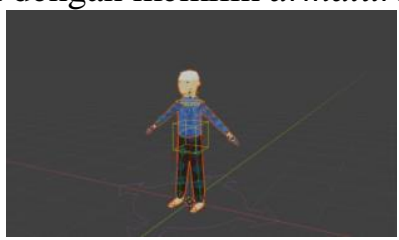

Gambar 7. Rigging Karakter

\subsubsection{Animating}

Proses animating dilakukan melalui pemberian key frame pada timeline. Sebelum itu, langkah awal yang dilakukan adalah membuat key pose agar metode pose to pose mudah diterapkan pada animasi. Key pose dibuat dan disimpan pada bagian Object Data >> Pose Library. Gambar 8 merupakan gambar dari beberapa key pose yang dibuat pada Pose Library.

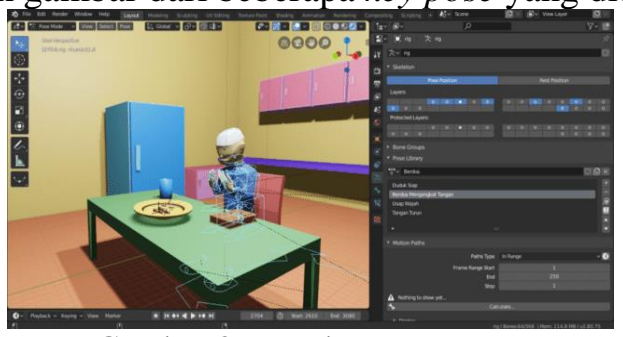

Gambar 8. Membuat Key Pose

Setelah membuat key pose, langkah selanjutnya adalah menempatkan key pose sebagai key frame pada timeline. Kemudian menambahkan pose tambahan di antara key pose agar animasi tampak lebih halus. Gambar 9 merupakan gambar pembuatan key frame untuk scene karakter berdoa.

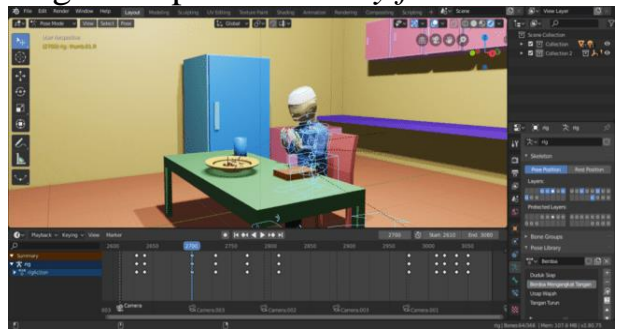

Gambar 9. Pembuatan Key Frame

Kemudian agar hasil render animasinya nanti bisa tampak bagus, maka pencahayaan dan kamera harus diatur. Penulis memberikan pencahayaan menggunakan Light Sun dan membuat 4 kamera serta menjadikannya sebagai marker kamera pada timeline.

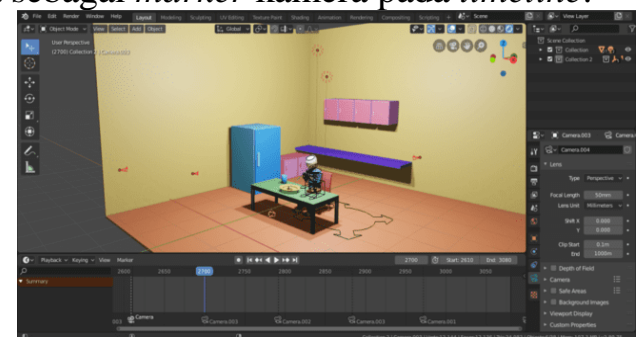

Gambar 10. Penempatan Kamera dan Pencahayaan

\subsubsection{Rendering}

Proses terakhir dari tahap produksi adalah rendering. Untuk melakukan render animasi membutuhkan waktu yang agak lama dari pada editing video. Kualitas video yang dipakai 
adalah 24fps atau 24 frame per second. Kemudian memberi resolusi sebesar 1920 X 1080 px, memilih format file FFmpeg Video, container MPEG-4, dan memasang audio codec mp3.

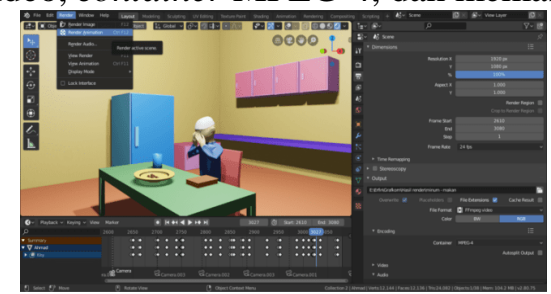

Gambar 11. Tahap Render Animasi Scene Berdoa

Gambar 12 adalah hasil render dari seluruh scene animasi yang berjumlah 8 scene yang disimpan pada folder Hasil Render.

đ $\rho$ Search Hasil render
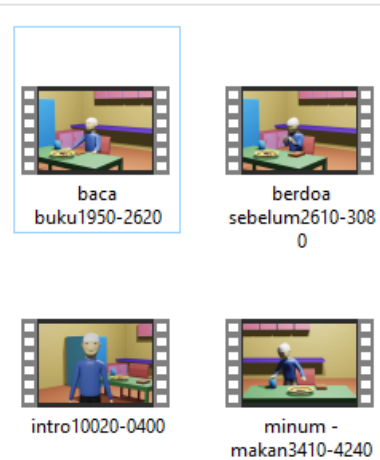
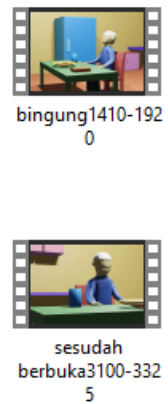

Gambar 12. Hasil Render Semua Scene Animasi

\subsection{Pasca Produksi}

\subsubsection{Final Editing}

Final editing dilakukan melalui software Blender dengan mengedit dan menggabungkan semua scene animasi mulai dari scene 1 sampai scene 8 sesuai urutan. Scene 1 berupa intro atau pembukaan animasi. Scene 2 berupa adegan karakter berjalan menuju meja makan. Kemudian scene 3 berupa adegan karakter bingung ingin melakukan sesuatu sambil menunggu adzan maghrib. Scene 4 berupa adegan membaca buku. Scene 5 berupa adegan berdoa sebelum berbuka puasa. Scene 6 berupa adegan berbuka. Scene 7, adegan setelah berbuka puasa. Dan scene 8 berupa penutupan animasi oleh karakter. Gambar 13 merupakan gambar proses final editing sedangkan gambar 14 adalah gambar hasil video animasi berdurasi 2 menit 50 detik yang sudah melalui tahap final editing.

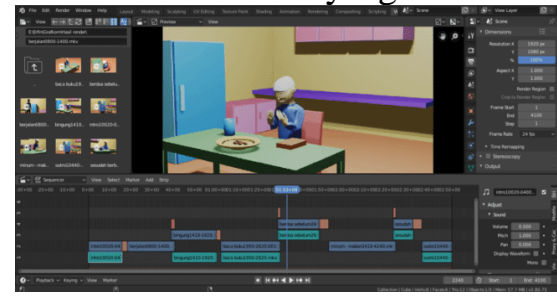

Gambar 13. Final Editing

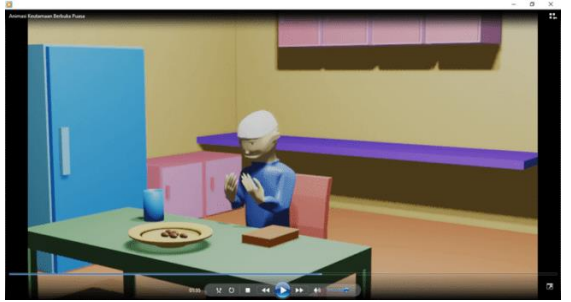

Gambar 14. Video Animasi 


\section{KESIMPULAN}

Animasi berjudul "Keutamaan Berbuka Puasa" berisi edukasi tentang bagaimana adab berbuka puasa yang baik. Berdasarakan penelitian tentang metode pose to pose untuk membuat animasi 3D islami keutamaan berbuka puasa yang sudah dilakukan, maka dapat disimpulkan bahwa video animasi berhasil dibuat sesuai prinsip pose to pose. Metode pose to pose dalam pembuatan animasi digunakan pada setiap scene sehingga menghasilkan gerakan yang halus. Selain itu, Animasi berhasil dibuat dengan sedikit perubahan adegan sehingga konsistensi cerita antara konsep awal dengan hasil animasi tetap sama. Dengan demikian, hasil video animasi dapat memberikan contoh adab berbuka puasa yang baik dan benar.

\section{REFERENSI}

[1] D. Suhardiman, "Pembuatan Simulasi Pergerakan Objek 3D menggunakan OpenGL," J. Tek. Elektro dan Komput., vol. 2, no. 1, pp. 1-6, 2012.

[2] Z. Azmi, "Implementasi grafika komputer untuk pembuatan animasi," Saintikom, vol. 10, no. 3, pp. 208-212, 2011.

[3] H. Nainggolan, "Perancangan Animasi Wayang Pandawa Lima dalam Lakon Pilkada dengan Menggunakan Metode Pose to Pose," Maj. Ilm. INTI, vol. 5, no. 1, pp. 64-69, 2017.

[4] Y. Syahfitri, "Teknik Film Animasi Dalam Dunia Komputer," J. SAINTIKOM, vol. 10, no. 3, pp. 213-217, 2011.

[5] A. Rachman and I. Nadiyati, "Dakwah Melalui Film Animasi," ORASI J. Dakwah dan Komun., vol. 9, no. 2, p. 29, 2018, doi: 10.24235/orasi.v9i2.3690.

[6] M. Mahfud and R. Kertamukti, "Desain Komunikasi Dakwah Visual Animasi 2d Untuk Anak.," Profetik J. Komun., vol. 9, no. 2, pp. 45-64, 2016.

[7] Z. Aziz, "Fluxus Animasi Dan Komunikasi Di Era Media Baru Digital," CHANNEL J. Komun., vol. 7, no. 1, p. 49, 2019, doi: 10.12928/channel.v7i1.13017.

[8] S. F. Salmon, V. Tulenan, and B. A. Sugiarso, "Penggunaan Metode Pose to Pose dalam Pembuatan Animasi 3D Tarian Minahasa Maengket," J. Tek. Inform., vol. 12, no. 1, pp. 1-9, 2017, doi: 10.35793/jti.12.1.2017.17867.

[9] Y. Affandi, N. Satia Nuryanto, E. Mahendra, and S. Eka Setiawan, "Implementasi Metode Pose to Pose dalam Pembuatan Animasi 2D Gerakan Ruku' Shalat," Respati, vol. 14, no. 1, pp. 12-16, 2019.

[10] I. H. Purwanto, L. Qodarsih, F. H. Majid, and K. A. Syamrahmarini, "Implementasi Pose To Pose Pada Simulasi Gerak Panda Berjalan Dengan Teknik Frame By Frame," Explore, vol. 9, no. 1, p. 43, 2019, doi: 10.35200/explore.v9i1.164.

[11] V. Waeo, A. S. M. Lumenta, and B. A. A. Sugiarso, "Implementasi Gerakan Manusia Pada Animasi 3D Dengan Menggunakan Menggunakan Metode Pose to pose," J. Tek. Inform., vol. 9, no. 1, pp. 1-8, 2016, doi: 10.35793/jti.9.1.2016.14641.

[12] K. T. Markova, T. A. Dovramadjiev, and G. V. Jecheva, "Computer parametric designing in Blender software for creating 3D paper models," Annu. J. Tech. Univ. Varna, Bulg., vol. 1, no. 1, pp. 77-84, 2017, doi: 10.29114/ajtuv.vol1.iss1.44.

[13] T. Zebua, B. Nadeak, and S. B. Sinaga, "Pengenalan Dasar Aplikasi Blender 3D dalam Pembuatan Animasi 3D," J. ABDIMAS Budi Darma, vol. 1, no. 1, pp. 18-21, 2020.

[14] J. Nari, V. Tulenan, S. Sentinuwo, Y. Rindengan, and O. Lantang, "Perancangan Studio Musik Bambu Dengan Perspektif Animasi 3D," J. Tek. Inform., vol. 4, no. 2, pp. 1-7, 2015, doi: 10.35793/jti.4.2.2014.6988.

[15] R. Muhammad and E. P. A. Sugara, "Sejarah Pembangunan Masjid Agung Palembang dalam Video Animasi 3 Dimensi," Gestalt, vol. 1, no. 2, pp. 227-240, 2019.

[16] S. Nofiadi, T. Listyorini, and A. Susanto, "Metamorfosis Kupu-Kupu," dSimetris, vol. 8, no. 1, pp. 299-308, 2017.

[17] M. F. Amelia and W. T. Atmojo, "Pengenalan Perusahaan Berbasis Animasi Pada CV Dhifarindo Global Dengan Metode Multimedia Development Life Cycle," J. Inov. 
Inform., vol. 3, no. 2, pp. 33-42, 2018.

[18] B. Yekti, "Studi Efektivitas Praktik Modeling Dalam Produksi Asset Animasi Stop Motion Menggunakan 3D Printing," Ultim. J. Komun. Vis., vol. 7, no. 2, pp. 36-46, 2016, doi: 10.31937/ultimart.v7i2.384.

[19] R. R. Punusingon, A. S. Lumenta, and Y. D. Y. Rindengan, "Animasi Sosialisasi Undang-Undang Informasi dan Transaksi Elektronik," J. Tek. Inform., vol. 12, no. 1, 2017, doi: 10.35793/jti.12.1.2017.17796.

[20] H. S. Suratinoyo, H. Wowor, J. Robot, and S. Karouw, "Cerita Rakyat Daerah Minahasa: Implementasi Short Film Animasi 3D," J. Tek. Inform., vol. 2, no. 2, 2013, doi: 10.35793/jti.2.2.2013.2709.

[21] U. A. Wildy, "Animating Karakter pada Film Animasi 3D Perjalanan Rempah Rempah," 2017.

[22] Y. Caroline, V. Tulenan, and B. A. Sugiarso, "Rancang Bangun Film Animasi 3 Dimensi Universitas Sam Ratulangi," J. Tek. Inform., vol. 9, no. 1, pp. 1-7, 2016, doi: 10.35793/jti.9.1.2016.14639.

[23] A. R. Putri et al., "Pembuatan Simulasi Perang Zaman Pertengahan dengan Metode Pose to Pose Menggunakan Software Blender," JISKA (Jurnal Inform. Sunan Kalijaga), vol. 6, no. 1, p. 1, 2021, doi: 10.14421/jiska.2021.61-01.

[24] M. V. Rompas, A. Sinsuw, J. Robot, and X. Najoan, "Perancangan Gedung Fakultas Teknik Unsrat Dengan Perspektif Animasi 3D," J. Tek. Inform., vol. 2, no. 2, 2013, doi: 10.35793/jti.2.2.2013.2332.

\section{Biodata Penulis}

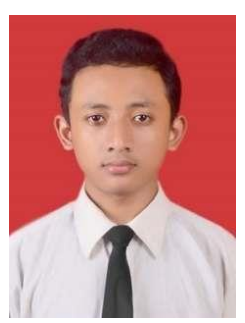

Mahadir Muhamad Erfin Abdilah lahir di kota Blitar pada tahun 2001. Pendidikannya di mulai dari MI Al-Huda, Kawedusan yang lulus pada tahun 2013. Kemudian melanjutkan di MTs N Kunir, Wonodadi, Blidar. Lulusan terakhir dari SMAN 1 Srengat pada tahun 2019. Dan saat ini sedang menempuh gelar Sarjana Komputer dari Universitas Islam Negeri Maulana Malik Ibrahim, Malang, Indonesia, tahun masuk 2019. Minat penelitiannya meliputi animasi, Internest of Things, robotik, drone, kecerdasan buatan, pemrograman web dan pembelajaran mesin.

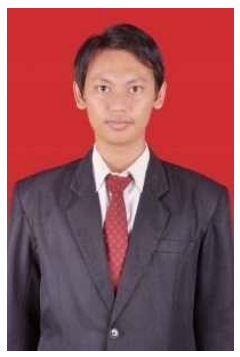

Juniardi Nur Fadilah memperoleh gelar Sarjana Komputer dari Universitas Islam Negeri Maulana Malik Ibrahim, Malang, Indonesia, pada tahun 2014. Dan menerima gelar M.Teknik di Jaringan Cerdas Multimedia, Departemen Teknik Elektro, Institut Teknologi Sepuluh Nopember (ITS), Surabaya, Indonesia tahun 2016. Minat penelitiannya meliputi teknologi game, animasi, Internest of Things, robotika, drone, kecerdasan buatan dan pembelajaran mesin.

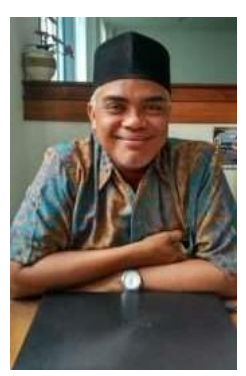

Fresy Nugroho memperoleh gelar Sarjana Teknik Elektro dari Universitas Brawijaya, Malang, Indonesia, pada tahun 1997. Dan menerima gelar M.Teknik di Departemen Teknik Elektro, Institut Teknologi Sepuluh Nopember (ITS), Surabaya, Indonesia tahun 2010. Saat ini sedang menempuh gelar Doktoral pada Jurusan Teknik Elektro, Institut Teknologi Sepuluh Nopember, Surabaya, Indonesia. Minat penelitiannya meliputi teknologi game, animasi, pendidikan, visi komputer, kecerdasan buatan, pembelajaran mesin dan Optimalisasi. 